\title{
lodixanol inhibits exogenous surfactant therapy in rats with acute respiratory distress syndrome
}

\author{
J. Kesecioglu*, M.J. Schultz", J.J. Haitsma ${ }^{\natural}$, G.J. den Heeten ${ }^{+}$, B. Lachmann
}

Iodixanol inhibits exogenous surfactant therapy in rats with acute respiratory distress syndrome. J. Kesecioglu, M.J. Schultz, J.J. Haitsma, G.J. den Heeten, B. Lachmann. C) ERS Journals Ltd 2002.

ABSTRACT: Optimal alveolar distribution of exogenous surfactant is an important determinant of its beneficial effect. This distribution can be determined by suspending surfactant in a radiological contrast medium before intratracheal instillation, followed by radiological imaging. Iodixanol is reported to be a safe contrast medium that causes no lung injury when instilled intratracheally.

In this study, the effects of surfactant suspended in saline were compared with surfactant suspended either in 4:1 saline-iodixanol $\left(64 \mathrm{mg}\right.$ iodine $\left.\cdot \mathrm{mL}^{-1}\right)$ or in $1: 1$ salineiodixanol $\left(160 \mathrm{mg}\right.$ iodine $\left.\cdot \mathrm{mL}^{-1}\right)$, on oxygenation and lung mechanics in a rat model of adult respiratory distress syndrome (ARDS) induced by lung lavage.

After the induction of ARDS, surfactant instillation improved oxygenation, total lung volume at inflation with a distending pressure of $35 \mathrm{cmH}_{2} \mathrm{O}$, lung volume at transpulmonary pressure of $5 \mathrm{cmH}_{2} \mathrm{O}$ and Gruenwald index. The effects of surfactant suspended in 4:1 saline-iodixanol were similar to those of surfactant alone. However, instillation of surfactant suspended in 1:1 saline-iodixanol resulted in significantly lower values in all measured parameters. Surface tension was the lowest in surfactant suspended in saline alone and addition of iodixanol led to an increase in surface tension in a dose-dependent manner.

In conclusion, iodixanol at the higher dose caused an inhibition of the exogenous surfactant effect, characterized as a lack of improvement in oxygen tension in arterial blood, low total lung compliance, volume at $5 \mathrm{cmH}_{2} \mathrm{O}$ end-expiration and Gruenwald index. This effect of iodixanol was probably due to its high surface tension, especially if a high concentration was used. Surfactant suspended in a lower concentration of iodixanol seems a better alternative, allowing for radiological imaging of the distribution of surfactant when intratracheally instilled.

Eur Respir J 2002; 19: 820-826.
*Dept of Anaesthesiology, Cardiothoracic and Neurosurgical Intensive Care Unit, University Medical Centre Utrecht, ${ }^{\#}$ Dept of Intensive Care, Academic Medical Centre, University of Amsterdam, "Dept of Anaesthesiology, Erasmus University Rotterdam and ${ }^{+}$Dept of Radiology, Academic Medical Centre, University of Amsterdam, the Netherlands.

Correspondence: J. Kesecioglu, Dept of Anesthesiology, Cardiothoracic and Neurosurgical Intensive Care Unit, Division of Perioperative Medicine and Emergency Care, University Medial Center Utrecht, Mail Stop E03-511, P.O. Box 85500,3508 GA Utrecht, The Netherlands.

Fax: 31302541828

E-mail: j.kesecioglu@azu.nl

Keywords: Exogenous surfactant iodixanol

lung lavage

oxygenation

respiratory distress

surface tension

\section{Received: July 32001}

Accepted after revision December 12 2001
Neonatal respiratory distress syndrome is characterized by immaturity of the lungs, resulting in relative absence of pulmonary surfactant [1]. In neonates with this syndrome, administration of exogenous surfactant intratracheally is the primary life-saving treatment [2]. In acute respiratory distress syndrome (ARDS), acute respiratory failure from altered ventilation/perfusion ratios, leading to hypoxaemia, hypoor hypercapnia and decreased lung compliance [3], is directly correlated with the disturbance of the pulmonary surfactant system [4-8]. Recent studies on intratracheal administration of exogenous surfactant in patients with ARDS have yielded controversial results. Although a multicentre study showed that there were no benefits to surfactant administration [9], others have demonstrated an improvement in oxygenation [10-14] and some randomized studies with small numbers of patients showed a trend towards improved mortality [15].

The beneficial effects of surfactant therapy are dependent on factors such as the dose and method of intratracheal administration. These factors determine the extent of distribution of surfactant in the alveoli. While the dose of surfactant to be given is usually known [15], there is no data currently available on the distribution of surfactant in the bronchoalveolar system, except as post mortem analysis in lung tissue [16]. A possible method to determine this distribution in vivo is by combining the surfactant with a contrast medium before intratracheal administration, followed by radiological imaging. It is important that the contrast medium used does not interfere with surfactant activity by increasing the surface tension at the alveolar level, as this may further impair optimal distribution of exogenous surfactant.

There are contradictory reports on the seriousness of adverse effects when commonly used contrast media are aspirated in the lungs [17-22]. However, it has been shown that nonionic and isotonic agents are well tolerated and cause fewer pulmonary complications than ionic and hyperosmolar agents [17-19, 23, 24]. LARSEN et al. [25] reported that single intratracheal instillation of the nonionic, iso-osmolar, dimeric contrast medium iodixanol was unlikely to cause any 
significant tissue damage or lead to respiratory complications in healthy rat lungs. However, there is no data on the effect of contrast media when instilled or accidentally ingested into the ARDS lung.

The authors hypothesized that iodixanol could be a suitable contrast medium to combine with surfactant to allow radiological imaging of the distribution of surfactant. It is known that different agents can alter the in vivo and in vitro properties of exogenous surfactant [26]. Therefore, the aim of the study was to find an iodixanol concentration to combine with surfactant, which would not alter the exogenous surfactant properties, as measured by gas exchange and lung mechanics in vivo and by surface tension in vitro, in a surfactant-deficient animal model.

\section{Materials and methods}

\section{Exogenous surfactant}

The surfactant (HL 10; Leo Pharmaceutical Products, Copenhagen, Denmark) used in these experiments was a freeze-dried natural surfactant isolated from minced pig lungs. It consisted of $\sim 90-95 \%$ phospholipids and 1\% hydrophobic proteins (surfactant protein (SP)-B and SP-C), the remainder being other lipids such as cholesterol, glyceride and free fatty acids. SP-A (the largest surfactant-associated protein, with a molecular weight of $26-38 \mathrm{kDa}$ ) was absent in this surfactant preparation. On the day of the experiments, fresh surfactant suspensions were prepared by diluting the freeze-dried surfactant in sterile saline or iodixanol mixtures.

\section{Iodixanol mixtures}

Iodixanol (Nycomed, Oslo, Norway) is a nonionic, iso-osmolar, dimeric, water-soluble contrast medium. All concentrations of iodixanol are isotonic with blood and have the same osmolarity as blood. On the day of the experiments, sterile saline was mixed 1:1 and 4:1 with iodixanol. The stock solution of iodixanol contained $320 \mathrm{mg}$ iodine $\cdot \mathrm{mL}^{-1}$.

\section{Animal study}

This study was approved by the Animal Care and Use Committee of the Erasmus University Rotterdam.

The study was performed in 30 male adult SpragueDawley rats (body weight 240-350 g). After induction of anaesthesia with nitrous oxide, oxygen and isoflurane $(65,33,2 \%$ respectively) a tracheotomy was performed and a catheter was inserted into the carotid artery. Anaesthesia was maintained with sodium pentobarbital $\left(60 \mathrm{mg} \cdot \mathrm{Kg}^{-1} \cdot \mathrm{h}^{-1} \quad\right.$ i.p. $)$ and muscle relaxation was attained with pancuronium bromide $\left(0.5 \mathrm{mg} \cdot \mathrm{Kg}^{-1} \cdot \mathrm{h}^{-1}\right.$ i.m. $)$. The lungs were ventilated with a Servo Ventilator 300 (SiemensElema, Solna, Sweden) at the following ventilator settings: pressure-controlled ventilation, inspiratory oxygen fraction $\left(\mathrm{Fi}, \mathrm{O}_{2}\right)$ 1.0, ventilation frequency
$30 \cdot \mathrm{min}^{-1}$, peak airway pressure $14 \mathrm{cmH}_{2} \mathrm{O}$, positive end-expiratory pressure (PEEP) $2 \mathrm{cmH}_{2} \mathrm{O}$ and inspiratory:expiratory ratio $1: 2$.

After reaching steady state (oxygen tension in arterial blood $\left.\left(\mathrm{Pa}, \mathrm{O}_{2}\right)>500 \mathrm{mmHg}\right)$, the rats were randomly divided into five groups, each consisting of six rats. Sham rats (Group I) were ventilated for 120 min with the ventilatory settings mentioned earlier. In Groups II-V, ARDS was induced by lung lavage, as described by LACHMANN et al. [4]. In brief, lungs were lavaged six to seven times with warm saline $\left(37^{\circ} \mathrm{C}, 30 \mathrm{~mL} \cdot \mathrm{kg}^{-1}\right)$ to produce a $\mathrm{Pa}, \mathrm{O}_{2}<80 \mathrm{mmHg}$ at a peak inspiration pressure of $26 \mathrm{cmH}_{2} \mathrm{O}$ and PEEP of $6 \mathrm{cmH}_{2} \mathrm{O}$. The ventilator settings were unchanged throughout the entire observation period. Approximately $5 \mathrm{~min}$ after $\mathrm{Pa}_{\mathrm{a}} \mathrm{O}_{2}<80 \mathrm{mmHg}$, Group II (control) received no treatment, Group III received surfactant suspended in sterile saline, Group IV received surfactant suspended in a 4:1 saline-iodixanol mixture (iodixanol concentration $64 \mathrm{mg}$ iodine $\cdot \mathrm{mL}^{-1}$ ) and Group V received surfactant suspended in a 1:1 saline-iodixanol mixture (iodixanol concentration $160 \mathrm{mg}$ iodine $\cdot \mathrm{mL}^{-1}$ ). Rats in Groups III-V were treated with a surfactant dose of $150 \mathrm{mg} \cdot \mathrm{Kg}^{-1}$. The surfactant preparation used in all groups was suspended in saline or saline-iodixanol mixture at a concentration of $40 \mathrm{mg} \cdot \mathrm{mL}^{-1}$. This resulted in a total volume of $\sim 3.7-4 \mathrm{~mL} \cdot \mathrm{kg}$ bodyweight ${ }^{-1}$. Mixtures used in all rats were incubated together for $30 \mathrm{~min}$ at $37^{\circ} \mathrm{C}$.

Blood samples for measurement of $\mathrm{Pa}_{\mathrm{a}} \mathrm{O}_{2}$ and carbon dioxide tension in arterial blood $\left(\mathrm{Pa}, \mathrm{CO}_{2}\right)$ were taken from the carotid artery at steady state and at 15, 30, 60, 90 and 120 min in Group I rats. In Groups II-V, these measurements were performed before lung lavage and $5 \mathrm{~min}$ after the last lavage (directly followed by treatment) and at 15, 30, 60, 90 and $120 \mathrm{~min}$ post-treatment. At the end of the experiment, animals were killed with an overdose of intra-arterial administered sodium pentobarbital. Subsequently, pressure/volume curves were recorded in all groups using the syringe technique (see later), followed by bronchoalveolar lavage (BAL) for determination of total-protein concentration.

\section{Pressurelvolume curves}

The static pressure/volume curves were recorded with the syringe technique. After the thorax and diaphragm were opened, the tracheostomy catheter was connected to a pressure transducer with a syringe attached to it (Validyne model DP 45-32; Validyne Engineering, Northridge, CA, USA) and pressures were recorded on a polygraph (Grass model 7B; Grass Instrument, Quincy, MA, USA). The lungs were first ventilated with nitrogen for 3-5 min. Subsequently, using a syringe filled with nitrogen, the lungs were first inflated (within $10 \mathrm{~s}$ ) to an airway pressure of $35 \mathrm{cmH}_{2} \mathrm{O}$ which was maintained for $5 \mathrm{~s}$, and then deflated to an airway pressure of $0 \mathrm{cmH}_{2} \mathrm{O}$. The lungs were then reinflated in steps of $0.5 \mathrm{~mL}$ until an airway pressure of $35 \mathrm{cmH}_{2} \mathrm{O}$ was reached. Each inflation step took $1-2 \mathrm{~s}$ followed by a 5 -s pause to allow 


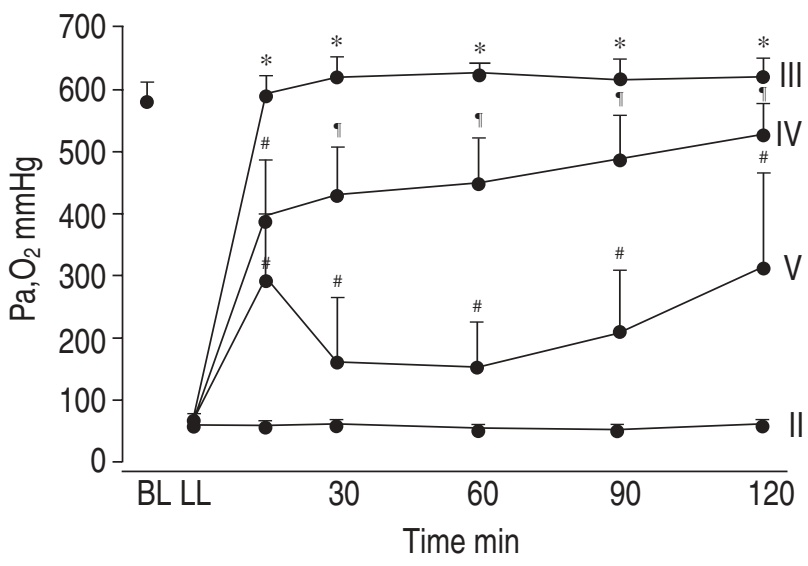

Fig. 1.-Changes in mean arterial oxygen tensions $\left(\mathrm{Pa}_{\mathrm{a}} \mathrm{O}_{2}\right)$ of the study groups before lung lavage $(\mathrm{BL})$, after lung lavage (LL) and $15,30,60,90$ and $120 \mathrm{~min}$ thereafter. Data are presented as mean \pm SD. Group II: control; III: treated with surfactant; IV: treated with surfactant suspended in 4:1 saline-iodixanol; V: treated with surfactant suspended in $1: 1$ saline-iodixanol. ${ }^{*}: \mathrm{p}<0.05$ versus Groups II, IV and V; ${ }^{\#}: \mathrm{p}<0.05$ versus Group; ${ }^{\top}: \mathrm{p}<0.05$ versus Groups II and V.

pressure equilibration. The lungs were then deflated in the same way until an airway pressure of $0 \mathrm{cmH}_{2} \mathrm{O}$ was reached. The volume left in the syringe was recorded. Total lung capacity was defined as lung volume at inflation with a distending pressure of $35 \mathrm{cmH}_{2} \mathrm{O}$ (TLC35).

The Gruenwald index, which characterizes the surfactant system in situ, was calculated from the pressure/volume curve, defined as:

$$
\left(\left(2 \times V_{5}\right)+V_{10}\right) /\left(2 \times V_{\max }\right)
$$

where $V 5, V 10$ and $V_{\max }$ are the lung volumes at transpulmonary pressures of 5,10 and $35 \mathrm{cmH}_{2} \mathrm{O}$ from the deflation limb, respectively [27].

\section{Bronchoalveolar lavage fluid}

The BAL samples of all rats were prepared as follows. All BAL samples were centrifuged for $5 \mathrm{~min}$ at $2,000 \times g$ to remove cell material. Protein concentration was determined with a photospectometer (Beckman DU 7400; Fullerton, CA, USA) at $595 \mathrm{~nm}$ using the method of BRADFORD [28] (Bio-Rad, Munich, Germany) with bovine serum albumin protein assay (Sigma, St Louis, MO, USA) as standard.

\section{Surface tension}

In Groups III-V the surface activity of surfactant alone and the two surfactant-iodixanol mixtures with different concentrations was measured with the Wilhelmy balance (E. Biegler GmbH, Mauerbach, Austria) by applying incremental doses of 10, 20 and $50 \mu \mathrm{L}$ of the mixtures to the surface of a saline-filled trough [29]. Surface area was compressed and expanded with a cycling time of $3 \mathrm{~min} \cdot \mathrm{cycle}^{-1}$ maximum and minimum surface area of 64 and $12.8 \mathrm{~cm}^{2}$, respectively (100\% and 20\%). Maximal and minimal surface tensions were measured after three cycles at $100 \%$ and $20 \%$ surface area, respectively, and are expressed as milli-Newton $(\mathrm{N}) \cdot \mathrm{m}^{-1}$.

\section{Statistical analysis}

Comparisons were analysed with repeated measures analysis of variance (ANOVA). If a difference was found, a post hoc test was performed (Tukey-Kramer). Statistical significance was set at $\mathrm{p}<0.05$. All data are expressed as mean $\pm \mathrm{SD}$.

\section{Results}

\section{Arterial blood gas values in Groups $I-V$}

In sham rats (Group I), $\mathrm{Pa}, \mathrm{O}_{2}$ values obtained at steady state and 15,30,60,90 and 120 min thereafter were $657 \pm 19,603 \pm 2,580 \pm 15,616 \pm 9,605 \pm 16$ and $609 \pm 8 \mathrm{mmHg}$, respectively. After induction of ARDS, $P \mathrm{a}, \mathrm{O}_{2}$ values in control rats (Group II) remained low during the entire study, whereas administration of surfactant in Group III caused a rapid and complete improvement in $\mathrm{Pa}, \mathrm{O}_{2}$ values. A slower improvement in $\mathrm{Pa}, \mathrm{O}_{2}$ values in rats treated with the surfactantiodixanol mixtures was seen in Groups IV and $\mathrm{V}$ (fig. 1). From $15 \mathrm{~min}$ on, $\mathrm{Pa}_{2} \mathrm{O}_{2}$ values obtained in Group III were significantly higher than those in the control rats (Group II) and rats that received surfactant-iodixanol mixtures (Groups IV and V) $(\mathrm{p}<0.05)$. From $30 \mathrm{~min}$ on, $\mathrm{Pa}_{2} \mathrm{O}_{2}$ values in rats in Group IV were significantly higher than those in Group V $(\mathrm{p}<0.05)$.

$P a, \mathrm{CO}_{2}$ values were significantly higher in Group II from the time of lung lavage onwards compared to all other groups $(\mathrm{p}<0.05)$ (table 1$). \mathrm{Pa}_{\mathrm{a}} \mathrm{CO}_{2}$ values were

Table 1.-Data on oxygen tension in arterial blood of all study groups

\begin{tabular}{llllllll}
\hline Group & BL & LL & 15 min & $30 \min$ & 60 min & 90 min & $120 \mathrm{~min}$ \\
\hline I & $23 \pm 3$ & & $24 \pm 3^{*}$ & $28 \pm 1^{*}$ & $30 \pm 2^{*}$ & $28 \pm 3^{*}$ & $29 \pm 3^{*}$ \\
II & $31 \pm 6$ & $70 \pm 24^{\#}$ & $77 \pm 27^{\#}$ & $76 \pm 31^{\#}$ & $83 \pm 36^{\#}$ & $84 \pm 36^{\#}$ & $70 \pm 20^{\#}$ \\
III & $38 \pm 15$ & $47 \pm 7^{\star}$ & $36 \pm 10^{*}$ & $31 \pm 5^{*}$ & $33 \pm 6^{*}$ & $29 \pm 5^{\star}$ & $30 \pm 6^{*}$ \\
IV & $47 \pm 9$ & $63 \pm 8$ & $51 \pm 5$ & $49 \pm 6$ & $50 \pm 4$ & $44 \pm 4$ & $44 \pm 7$ \\
V & $37 \pm 9$ & $53 \pm 13$ & $41 \pm 10$ & $46 \pm 13$ & $50 \pm 12$ & $49 \pm 12$ & $48 \pm 13$ \\
\hline
\end{tabular}

Data is presented as mean \pm SD. BL: before lavage; LL: repeated lavage with saline to induce lung injury; Group I: sham; Group II: control; Group III: treated with surfactant; Group IV: treated with surfactant suspended in 4:1 saline-iodixanol; Group V: treated with surfactant suspended in 1:1 saline-iodixanol. *: $\mathrm{p}<0.05$ versus Group II, IV and V; ${ }^{*}$ p $<0.05$ versus Group I, III, IV and IV; ${ }^{\uparrow}$ : $\mathrm{p}<0.05$ versus Group IV and V. 
Table 2. - Data from all study groups, showing lung volume at inflation with a distending pressure of $35 \mathrm{~cm} \mathrm{H}_{2} \mathrm{O}(\mathrm{TLC} 35)$, Gruenwald index and total protein concentration (TPC)

\begin{tabular}{|c|c|c|c|c|c|}
\hline Study Group & I & II & III & IV & $\mathrm{V}$ \\
\hline TLC35 $\mathrm{mL} \cdot \mathrm{kg}^{-1}$ & $49.9 \pm 1.8$ & $35.3 \pm 0.8^{*}$ & $52.0 \pm 4.6^{\#}$ & $51.2 \pm 4.6^{\#}$ & 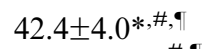 \\
\hline Gruenwald index & $1.04 \pm 0.08$ & $0.41 \pm 0.01 *$ & $0.83 \pm 0.08 *$, \# & $0.82 \pm 0.07 *$, \# & 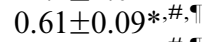 \\
\hline $\mathrm{TPC} \mathrm{mg} \cdot \mathrm{mL}^{-1}$ & $0.25 \pm 0.02$ & $1.27 \pm 0.37 *$ & $0.82 \pm 0.03^{*, \#}$ & $0.88 \pm 0.15^{*, \#}$ & $0.91 \pm 0.10^{*, \#, \emptyset}$ \\
\hline
\end{tabular}

Data are presented as mean \pm SD. Group I: sham; Group II: control; Group III: treated with surfactant; Group IV: treated with surfactant suspended in 4:1 saline-iodixanol; Group V: treated with surfactant suspended in 1:1 saline-Iodixanol. *: $\mathrm{p}<0.05$ versus group I; ${ }^{\#}: \mathrm{p}<0.05$ versus Group II; ${ }^{\uparrow}: \mathrm{p}<0.05$ versus Group III and IV.

significantly lower in Group III from 30 min onwards compared to Groups IV and V $(\mathrm{p}<0.05)$ (table 1$)$. There was no significant difference in $\mathrm{Pa}_{2} \mathrm{CO}_{2}$ values between Groups IV and V.

\section{Pressurelvolume curves in Groups $I-V$}

Data derived from the pressure/volume curves of all groups are given in table 2 and figure 2. TLC35 was significantly higher in Groups I, III, IV and V than in the control group $(\mathrm{p}<0.05)$ (table 2). Rats that received surfactant suspended in 1:1 saline-iodixanol had significantly lower TLC35 than rats in Groups I, III and IV. Significantly higher $V 5$ were measured in Groups III and IV compared to Groups II and V $(\mathrm{p}<0.05)$ (fig. 2). The Gruenwald Index was significantly lower in Groups II and V than in the other groups (table 2).

\section{Surface tension}

Surface tension values of surfactant and surfactantiodixanol mixtures are shown in figure 3. Surfactant dissolved in saline had the lowest minimum surface tension compared to the other mixtures. Surfactant

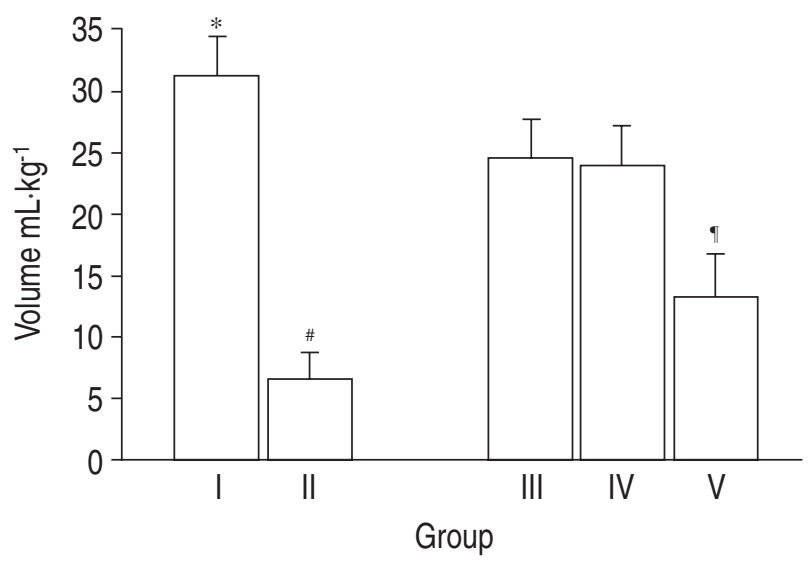

Fig. 2.-Lung volumes at transpulmonary pressures of $5 \mathrm{cmH}_{2} \mathrm{O}$ from the deflation limb of the pressure/volume curve of the study groups. Data are presented as mean \pm SD. Group I: sham; II: control; III: treated with surfactant; IV: treated with surfactant suspended in 4:1 saline-iodixanol; $\mathrm{V}$ : treated with surfactant suspended in 1:1 saline-iodixanol. *: $\mathrm{p}<0.05$ versus Groups II, III, IV and V; ${ }^{\#}: \mathrm{p}<0.05$ versus Group III, IV and V; ${ }^{\bullet}: \mathrm{p}<0.05$ versus Group III and IV. suspended with 1:1 saline-iodixanol had a significantly higher minimum surface tension than surfactant alone or surfactant suspended with 4:1 saline-iodixanol. Increasing the concentration of surfactant resulted in a further decrease in minimum surface tension of surfactant alone and surfactant mixed with 4:1 salineiodixanol. Surfactant mixed with 1:1 saline iodixanol was not affected by an increase of surfactant concentration.

\section{Protein content of bronchoalveolar fluid}

The protein concentrations measured in BAL fluid of sham rats and Groups II-V are given in table 2. All treated groups had significantly higher protein concentrations than sham rats. Group II had the highest concentration of proteins and this value was significantly higher than that in all other groups.

\section{Discussion}

In this study, iodixanol was used as a contrast agent because it has been reported to be a safe agent when aspirated or directly instilled in the lungs [25]. Aspiration of a contrast media used for the roentgen

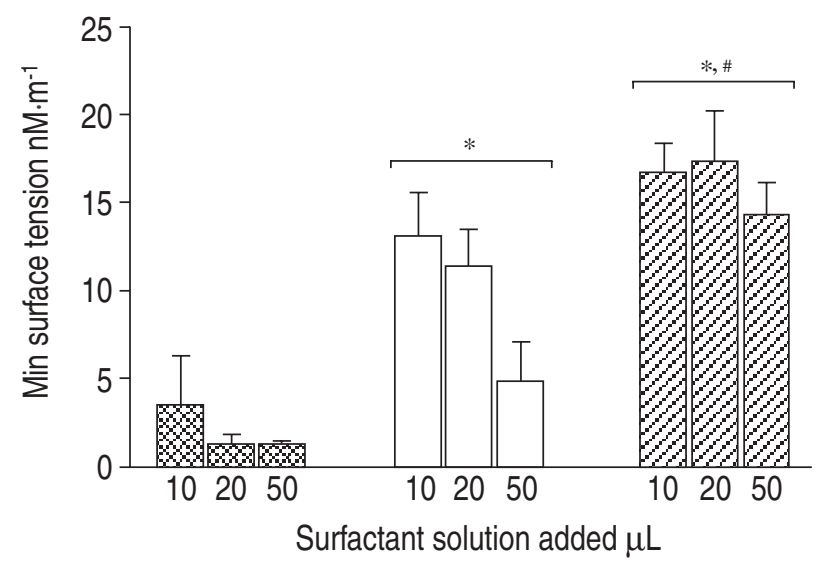

Fig. 3.-Mean surface tension values of surfactant suspended in saline ( $\mathbf{G}), 4: 1$ saline-iodixanol $(\square)$ and 1:1 saline-ioxidinal $(\mathbb{Z})$, made with three different surfactant doses of 10,20 and $50 \mu \mathrm{L}$. Data are presented as mean \pm SD. Values with three different surfactant doses were compared between groups. *: $\mathrm{p}<0.05$ versus surfactant suspended in saline; \#: $\mathrm{p}<0.05$ versus surfactant suspended in 4:1 saline-iodixanol. 
examination of the upper gastrointestinal tract may cause severe respiratory insuffficiency. Studies have therefore been performed in rats $[17-19,22,30,31]$, guinea pigs [23], rabbits [20,21] and dogs [18] to assess the damage of aspiration of commonly used watersoluble contrast media. As a result, it has been established that although some of these contrast media are not suitable to use for intrabronchial diagnostic procedures, other nonionic media did not cause harm to the respiratory system [17-24, 31]. Similarly, LARSEN et al. [25] reported that nonionic iso-osmolar contrast media, including iodixanol, when instilled intratracheally did not induce lung tissue damage or lead to respiratory complications.

The results of this study show that in rats with induced ARDS, iodixanol administered intratracheally, inhibits the effect of exogenously administered surfactant in a dose-dependent manner. This effect was indicated by a lack of improvement of $\mathrm{Pa}, \mathrm{O}_{2}$ and low TLC35, V5 and Gruenwald index values and was more prominent when surfactant was dissolved in higher concentrations of saline-iodixanol. This data contrasts with the findings of LARSEN et al. [25] concerning the effects of iodixanol. An important factor contributing to this contrast is the difference in methodology used. All the previous studies used animals with healthy lungs [17-24, 30, 31]. The same was true for LARSEN et al. [25] who used rats with healthy lungs and showed that iodixanol did not cause tissue damage or lead to respiratory complications. This study was performed on rats with injured lungs who needed mechanical ventilation with high pressures and an $\mathrm{Fi}_{1} \mathrm{O}_{2}$ of 1.0 to survive. The respiratory effects of iodixanol would probably not cause significant symptoms and changes in the histopathology of a healthy lung, especially if this effect was transient. Conversely, even minor damage can have deleterious effects on lung function and the oxygenation of ARDS lungs, as seen in the ARDS model in this study.

Another difference was that in the previous studies, animals were either intubated or a temporary tracheostomy was performed for the instillation of the contrast media, and breathing was spontaneous thereafter $[17-25,30,31]$. Instillation of saline was commonly used for control animals. Although the amount of saline used was significantly lower than in animal ARDS models, it is not the ideal placebo to use for intratracheal instillations [17, 21, 30], as saline, due to its high surface tension, impairs lung function. LARSEN et al. [25] based their judgement of contrast media on the histopathological examination, which was performed, at the earliest, at $6 \mathrm{~h}$ and, at the latest, on day 7. They showed that the majority of animals treated with iodixanol were unaffected compared to the control group, which received saline. In this study, all animals were anaesthetized, had an arterial cannula, received muscle relaxants and were mechanically ventilated. This allowed for ventilation of the lungs in steady state and for frequent blood gas measurements to be performed to determine the immediate changes of lung function during the trial. It was noted that surfactant improved the oxygenation. Adding iodixanol to surfactant (especially at a higher concentration) decreased the improvement of $P \mathrm{a}, \mathrm{O}_{2}$ in injured lungs. More importantly, $\mathrm{Pa}, \mathrm{O}_{2}$ values were constantly high in both the sham and surfactant groups, but constantly low in the untreated group. This showed that the lower $\mathrm{Pa}, \mathrm{O}_{2}$ values in Groups IV and $\mathrm{V}$ were completely dependent on the iodixanol concentration used. In both iodixanol groups, a timedependent gradual increase of $\mathrm{Pa}, \mathrm{O}_{2}$ was observed. This improvement did not reach the level of the sham or surfactant group within the study period of $120 \mathrm{~min}$, especially in Group V. However, it was suggested that the iodixanol effect was temporary, probably depending on its rate of metabolism. If no permanent damage occurred in the lungs, histopathological examinations performed at a later stage would certainly be normal.

The mechanism of the iodixanol effect on the lungs can be explained by the results obtained from the measurements of surface tension of the mixtures instilled. As expected, surfactant had a very low surface tension. When the amount measured was increased from 10 to $50 \mu \mathrm{L}$, surface tension decreased even further. Surfactant combined with 4:1 salineiodixanol at an amount of $10 \mu \mathrm{L}$, had much higher surface tension, although this improved significantly when the amount of surfactant was increased to $50 \mu \mathrm{L}$. In contrast, surfactant mixed with 1:1 salineiodixanol not only had the highest surface tension but was also unaffected by the increase in the amount of surfactant. This model of ARDS caused by lung lavage is characterized by surfactant deficiency. In the absence of surfactant, the stability of the fluid balance in the lungs is disturbed, leading to lung oedema. This is evidenced by the increase of total protein concentration measured in BAL fluid in all rats who had lung lavage compared to sham animals. Furthermore, after lung lavage, the surface tension at the air/liquid interface is much higher than normal and hence higher pressures are required to maintain lung aeration. Administration of surfactant improved lung function by decreasing the surface tension of the interface between alveoli and air. There was also an improvement of lung function with the mixture of surfactant with 4:1 saline-iodixanol. However, when surfactant was mixed with 1:1 saline-iodixanol, its beneficial effect was mostly inhibited, resulting in high surface tension at air/liquid interface and, therefore, only minor improvement of oxygenation.

This situation was also confirmed by the post mortem lung-mechanic data. TLC35 was significantly lower in the high-dose iodixanol group (Group V) than in the lower-dose iodixanol (Group IV) and surfactant group Groups (III). This showed that at the same pressure level, the lungs of the rats in Groups III and IV could receive much higher volumes due to lower surface tension at the air-liquid interface and higher lung compliance compared to lungs of rats in Group V. Similarly, V5 values were higher in groups receiving surfactant and surfactant dissolved in $4: 1$ saline-iodixanol mixture compared to rats receiving surfactant dissolved in 1:1 saline-iodixanol mixture. This meant that at an expiratory pressure value of $5 \mathrm{cmH}_{2} \mathrm{O}$, more volume of air was available in the rat lungs of Groups III and IV, showing that the lungs 
were more open and compliant at expiration than in Group $\mathrm{V}$ and thus allowing prolonged gas exchange at end expiration. Finally, the Gruenwald index results characterizing the surfactant system in situ, confirmed that the surfactant was less effective when dissolved in a high concentration of iodixanol.

In conclusion, iodixanol causes a temporary inhibition of exogenous surfactant, administered to the lungs of rats with adult respiratory distress syndrome. This effect is more prominent when surfacant is dissolved in a higher concentration of saline-iodixanol. The inhibitive effect of iodixanol is probably due to its high surface tension, which also affects the distribution of the surfactant. These results suggest that although no damage is shown to occur with intratracheal instillation of iodixanol in healthy lungs, it may have a deleterious effect on injured lungs if instilled or accidentally ingested. Use of a lower concentration has less effect on respiratory functions and has a lower surface tension. Therefore, it is unlikely that it will significantly affect the distribution of the instilled surfactant. For this reason, this suspension appears to be a safer alternative to be used for intratracheal administration, radiodiagnostic procedures and experimental studies on the distribution of surfactant in the lungs.

Acknowledgements. The authors would like to thank Leo Pharmaceutical Products (Copenhagen, Denmark) for supplying the Surfactant, S. Krabbendam for expert technical assistance and L. Visser-lsles for English language editing.

\section{References}

1. Avery ME, Fletcher BD, Williams RG. The lung and its disorders in the newborn infant. In: Schaffer AJ, eds. Major problems in clinical paediatrics (4th Edn). Philadelphia, WB Saunders, 1981; pp. 222 302.

2. Kattwinkel J. Surfactant-evolving issues. In: Goldsmith JP, Spitzer AR, eds. Controversies in neonatal pulmonary care. Clin perinatol. Philadelphia, WB Saunders, 1998; pp. 17-32.

3. Asbaugh DG, Bigelow DB, Petty TL, Levine BE. Acute respiratory distress in adults. Lancet 1967; 2: $319-323$.

4. Lachmann B, Robertson B, Vogel J. In vivo lung lavage as an experimental model of the respiratory distress syndrome. Acta Anaesthesiol Scand 1980; 24: 231-236.

5. Hanly P, Light RB. Lung mechanics, gas exchange, pulmonary perfusion and hemodynamics in a canine model of acute pseudomonas pneumonia. Lung 1987; 165: 305-322.

6. Henry JN, McArdle AH, Bounous G, Hampson LG, Scott LJ, Gurd FN. The effect of experimental hemorragic shock on pulmonary alveolar surfactant. J Trauma 1967; 7: 691-726.

7. Von Wichert P, Kohl FV. Decreased dipalmitoyllecithin content found in lung specimens from patients with so-called shock-lung. Intensive Care Med 1977; 3: $27-30$.
8. Petty TL, Silvers GW, Paul GW, Stanford RE. Abnormalities in lung elastic properties and surfactant function in adult respiratory distress syndrome. Chest 1979; 75: 571-574.

9. Anzueto A, Baughman RP, Guntupalli KK, et al. Aerosolized surfactant in adults with sepsis-induced acute respiratory distress syndrome. NEJM 1996; 22 : 1417-1421

10. Lachmann B, Gommers D. Surfactant treatment for neonatal lung diseases other than the idiopathic respiratory distress syndrome. Lung Respir 1994; 11: 35-39.

11. Richman PS, Spragg RG, Robertson B, Merritt TA, Curstedt $\mathrm{T}$. The adult respiratory distress syndrome: first trials with surfactant replacement. Eur Respir J Suppl 1989; 2: 109s-111s.

12. Perez-Benavides F, Riff E, Franks C. Adult respiratory distress syndrome and artificial surfactant replacement in the pediatric patient. Pediatr Emerg Care 1995; 11: 153-155.

13. Knoch M, Höltermann W, Lukasewitz P, Bittersohl J. Behandlung einer Totalatelektase der linken lunge bei schwerem ARDS nut seitengetrennter beatmung und Surfactant-Applikation. Anasthesiol Intensivmed Notfallmed Schmertzther 1995; 30: 270-273.

14. Suzuki H, Ohta T, Iwata Yamaguchi K, Sato T. Surfactant therapy for respiratory failure due to neardrowning. Eur J Pediatr 1996; 155: 383-384.

15. Gregory TJ, Steinberg KP, Spragg R, et al. Bovine surfactant therapy for patients with acute respiratory distress syndrome. Am J Respir Crit Care Med 1997; 155: $1309-1315$.

16. Segerer $\mathrm{H}$, van Gelder $\mathrm{W}$, Angenent $\mathrm{FW}$, et al. Pulmonary distribution and efficacy of exogenous surfactant in lung-lavaged rabbits are influenced by the instillation technique. Pediatr Res 1993; 34: 490494.

17. Ginai AZ, Bubberman A, Zondervan PE, Van Leeuwen W, Morcos SK. The histological response of the lungs to potentially suitable water-soluble bronchographic contrast agents iotrolan (a non-ionic dimer) and iopamidol (a non-ionic monomer). $\mathrm{Br}$ J Radiol 1993; 6: 773-777.

18. McAlister WH, Askin FB. The effect of some contrast agents in the lung. An experimental study in rat and dog. AJR 183; 140: 245-251.

19. Miyazawa T, Sho C, Nakagawa H, Oshino N. Effects of water-soluble contrast medium on the lungs in rat. Comparison of iotrolan, iopamidol and diatrizoate. Invest Radiol 1990; 25: 999-1003.

20. Moore DE, Carrol FE, Dutt PL, Redd GW, Holburn GE. Comparison of nonionic and ionic contrast agents in the rabbit lung. Invest Radiol 1991; 26: 134-142.

21. Rust RJ, Cohen MD, Ulbright TM. Clinical, radiographic and pathologic effects of Amipaque on rabbit lung. Comparison with barium and Gastrografin. Acta Radiol 1982; 23: 553-559.

22. Wells HD, Hyrnchak MA, Burbridge BE. Direct effects of contrast media on rat lungs. J Can Assoc Radiol 1991; 42: 261-264.

23. Gmeinweiser J, Erhardt W, Reiman HJ, Babic R, Speck U, Wenzel-Hora B. Side-effects of water-soluble contrast agents in the upper gastrointestinal tract. Invest Radiol 1990; 25: 27-28.

24. Thomsen HS, Dorph S. High-osmolar and low-osmolar 
contrast media. An update on frequency of adverse drug reactions. Acta Radiol 1993; 34: 205-209.

25. Larsen LE, Grant D, Walday $\mathrm{P}$. Tissue reaction following intratracheal application of roentgen contrast media in rats. Acta Radiol 1995; 36: 258-261.

26. Veen van't A, Gommers D, Mouton JW, Klujtmans JA, Kriit EJ, Lachmann B. Exogenous pulmonary surfactant as a drug delivering agent: influence of antibiotics on surfactant activity. $\mathrm{Br} J$ Pharmacol 1996; 118: 593-598.

27. Gruenwald P. A numerical index stability of lung expansion. J Appl Physiol 1963; 88: 359-367.

28. Bradford MM. A rapid and sensitive method for the quantitation of microgram quantities of protein utilizing the principle of protein-dye binding. Anal Biochem 1976; 72: 248-254.

29. Notter RH. Surface chemistry of pulmonary surfactant: the role of individual components. In: Robertson B, van Golde LMG, Batenburg JJ, eds. Pulmonary surfactant. Amsterdam, Elsevier, 1984; pp. 17-65.

30. Aufferman W, Geisel T, Wohlmann D, Gunther RW. Tissue reaction following endobronchial application of iopamidol and ioxithalamate in rats. Eur $J$ Radiol 1998; 8: 13-17.

31. D'Agostino HRV, Liebig RJ, McGovern M, Weinshelbaum A, Reich SB. Effects of iopamidol and iohexol in rat lungs following experimental aspiration. Invest Radiol 1989; 24: 899-902. 